\title{
KAJIAN KEARIFAN LOKAL MASYARAKAT DESA NGADAS TERHADAP PENGEMBANGAN EKOWISATA DI TAMAN NASIONAL BROMO TENGGER SEMERU JAWA TIMUR
}

(Study of Local Civility of Ngadas Village Communities on Development of Ecotourism in Bromo Tengger Semeru National Park East Java)

\author{
Fahrizal Gifari ${ }^{1 *}$, Tatag Muttaqin ${ }^{2}$, Ramli Ramadhan ${ }^{2}$ \\ ${ }^{1}$ Mahasiswa Jurusan Kehutanan, Fakultas Pertanian Peternakan, Universitas Muhammadiyah \\ Malang \\ ${ }^{2}$ Jurusan Kehuutanan, Fakultas Pertanian Peternakan, Universitas Muhammadiyah Malang \\ *Email: fahrizalgifari23@gmail.com
}

\begin{abstract}
Bromo Tengger Semeru National Park (TNBTS) is a complex area of approximately 50,276 Ha in the mountainous region, covering three famous landscapes namely Mount Bromo, Tengger Caldera and Mount Semeru. Based on the Decree of the Director General of PHKA No. 68 / Kpts / Dj-VI / 1998, TNBTS zoning consists of: Core Zone 22,006 Ha; Jungle Zone 23.485,20 Ha; Intensive Use Zone $425 \mathrm{Ha}$; Traditional Use Zone 2,360 Ha; and the 2,000 Ha Rehabilitation Zone.

This study aims to examine the local wisdom adopted by the community in Ngadas Village. When the research began in June-July 2019 and the research method used was a qualitative method, using the Phenomenology approach. An interesting phenomenon of research is the existence of Bromo Tengger Semeru National Park, Poncokusumo District, Malang Regency. Data collection techniques using in-depth interviews and closed questionnaires, observation and study of documents or literature

The majority of Ngadas people belong to the Tengger tribe, a tribe that is also scattered in villages near Mount Bromo in Pasuruan and Probolinggo districts where the majority of Tengger are Hindu. The Ngadas community has several traditional events such as Karo, Kasada, and Unan-unan.

Keywords: Local wisdom, TNBTS, Ngadas Village
\end{abstract}

\section{INTISARI}

Taman Nasional Bromo Tengger Semeru (TNBTS) adalah kompleks area seluas sekitar $50.276 \mathrm{Ha}$ di wilayah pegunungan, meliputi tiga lanskap terkenal yaitu Gunung Bromo, Kaldera Tengger dan Gunung Semeru. Berdasarkan SK Dirjen PHKA No. 68/Kpts/Dj-VI/1998, zonasi TNBTS terdiri dari: Zona Inti $22.006 \mathrm{Ha}$; Zona Rimba 23.485,20 Ha; Zona Pemanfaatan Intensif $425 \mathrm{Ha}$; Zona Pemanfaatan Tradisional 2.360 Ha; dan Zona Rehabilitasi $2.000 \mathrm{Ha}$.

Penelitian ini bertujuan untuk mengkaji kearifan lokal yang diterapkan oleh masyarakat Di Desa Ngadas. Waktu penelitian dimulai bulan Juni-Juli 2019 dan metode penelitian yang digunakan adalah metode kualitatif, menggunakan pendekatan Fenomenologi. Fenomena menarik penelitian adalah keberadaan kawasan wisata Taman Nasional Bromo Tengger Semeru, Kecamatan Poncokusumo, Kabupaten Malang. Teknik pengumpulan data menggunakan wawancara mendalam dan kuisioner secara tertutup, observasi dan teknik studi dokumen atau literatur.

Masyarakat Ngadas mayoritas bersuku Tengger, suku yang juga tersebar di desa-desa dekat gunung Bromo yang ada di Kabupaten Pasuruan dan Kabupaten Probolinggo dimana mayoritas suku Tengger beragama Hindu. Masyarakat Ngadas memiliki beberapa acara adat seperti Karo, Kasada, dan Unan-unan.

Kata Kunci: Kearifan lokal, TNBTS, Desa Ngadas 


\section{PENDAHULUAN}

Taman Nasional Bromo Tengger Semeru (TNBTS) adalah kompleks area seluas sekitar $50.276 \mathrm{Ha}$ di wilayah pegunungan, meliputi tiga lanskap terkenal yaitu Gunung Bromo, Kaldera Tengger dan Gunung Semeru. Berdasarkan SK Dirjen PHKA No. 68/Kpts/Dj-VI/1998, zonasi TNBTS terdiri dari: Zona Inti $22.006 \mathrm{Ha}$; Zona Rimba 23.485,20 Ha; Zona Pemanfaatan Intensif $425 \mathrm{Ha}$; Zona Pemanfaatan Tradisional $2.360 \mathrm{Ha}$; dan Zona Rehabilitasi $2.000 \mathrm{Ha}$. Taman Nasional adalah kawasan pelestarian alam baik daratan maupun perairan yang mempunyai ekosistem asli, yang dikelola dengan sistem zonasi yang dimanfaatkan untuk tujuan penelitian, ilmu pengetahuan, pendidikan, menunjang budidaya, budaya, pariwisata dan rekreasi. Sayektiningsih, dkk (2008) menyatakan bahwa Dataran tinggi Bromo Tengger Semeru kekhasan berupa enclave dalam kawasan konservasi.

Desa Ngadas Malang berada dalam area teritorial Taman Nasional Bromo Tengger Semeru (TNBTS). Berada di ketinggian 2.150 meter di atas permukaan laut menjadikan Desa Ngadas Bromo ini menjadi salah satu desa tertinggi yang ada di Jawa. Tak heran kalau banyak orang menyebutnya Desa Atas Awan di Malang. Desa Ngadas Malang terletak di Kecamatan Poncokusumo dan berada di ujung paling timur Kabupaten Malang, berbatasan langsung dengan wilayah Kabupaten Lumajang, Jawa Timur. Masyarakat suku Tengger memiliki kearifan lokal yang masih dipertahankan. Jika dilihat dari peran serta masyarakat dalam pengelolaan alam, konsep kearifan alam biasanya dapat ditemui pada nyanyian-nyanyian, pepatahpepatah, sesanti, petuah, semboyan, dan kitab-kitab kuno yang melekat dalam perilaku kehidupan sehari-hari. Persoalan yang dihadapi oleh masyarakat disana ialah tidak menyadari bahwasanya pengaruh modernisasi berjalan seiringan dengan kearifan lokal yang ada disana dan rawan akan terjadinya modernisasi dikarenakan terbuka untuk umum. Adapun penelitian ini dilakukan untuk mengkaji kearifan lokal masyarakat Desa Ngadas terhadap pengembangan ekowisata. Suku Tengger yang berdiam disekitar kawasan gunung Bromo yang terletak di kabupaten Probolinggo, Jawa Timur. Berdasarkan persebaran bahasa dan pola kehidupan sosial masyarakat, daerah persebaran suku Tengger adalah disekitar Probolinggo, Lumajang, (Ranupane kecamatan Senduro), Malang (desa Ngadas Kecamatan Poncokusumo), dan Pasuruan. Sementara pusat kebudayaan aslinya adalah di sekitar pedalaman kaki gunung Bromo.

Menurut Organisasi Pariwisata Dunia (UN-WTO, 2010), pariwisata merupakan salah satu industri yang berkembang pesat di dunia. Pariwisata bahkan menjadi sumber utama bagi pendapatan negara. Selain itu, pariwisata juga memberikan banyak efek bagi suatu negara, seperti lapangan pekerjaan yang dapat membantu merevitalisasi ekonomi lokal. Sektor pariwisata suatu Negara wajib dikembangkan agar negara tersebut dapat menarik minat para wisatawan untuk berkunjung ke negara mereka.

\section{METODE PENELITIAN}

Penelitian dilakukan pada bulan Mei 2019 s/d Juni 2019 yang berlokasi di Taman Nasional Bromo Tengger Semeru yang berfokus pada masyarakat desa Ngadas Kecamatan Poncokusumo Kabupaten Malang Jawa Timur.

Metode penelitian yang digunakan adalah metode kualitatif, menggunakan pendekatan Fenomenologi. Teknik pengumpulan data menggunakan wawancara mendalam dan kuisioner secara tertutup, observasi dan tekhnik studi dokumen atau literature. 


\section{Hasil dan Pembahasan}

Luas kawasan Taman Nasional Bromo Tengger Semeru secara umum sekitar $50.276,3$ ha. Zonasi TNBTS terdiri dari : Zona Inti 22.006 ha, Zona Rimba 23.485,20 ha, Zona Pemanfaatan Intensif 425 ha, Zona Pemanfaatan Tradisional 2.360 ha, dan Zona Rehabilitasi 2.000 ha.

Desa Ngadas tergolong dalam zona pemanfaatan tradisional dengan luas wilayah desa 395 ha. Kondisi geografis yang dekat dengan dua gunung, yaitu gunung Bromo dan gunung Semeru. Desa yang memiliki kepala keluarga 512 memiliki budaya yang sangat kuat salah satunya unan-unan yang diadakan dalam jangka waktu 5 tahun sekali.

Masyarakat Ngadas mayoritas bersuku Tengger, suku yang juga tersebar di desadesa dekat gunung bromo yang ada di Kabupaten Pasuruan dan Kabupaten Probolinggo dimana mayoritas suku Tengger beragama Hindu. Masyarakat Ngadas memiliki beberapa acara adat seprti Karo, Pthekan, Pujan, Kasada, Barikan, Mayu Dusun dan Unan-unan.

Unan-unan merupakan salah satu budaya yang dimiliki suku Tengger, tradisi ini dilakukan sebagai upaya penolak bala dan bersih desa. Istilah Unan-unan berasal dari kata Tuno yang artinya berkurang. Dalam penanggalan suku Tengger, setiap bulan memiliki 30 hari. Sementara pada bulan tertentu memiliki 29 hari. Sehingga jika dijumlah memiliki selisih lima hingga enam hari dalam setahun. Untuk melengkapi kekurangan tersebut, selisih hari itu dimasukkan dalam bulan Dhesta atau bulan kesebelas yang hanya ada dalam penanggalan tiap lima tahun sekali. Sehingga pada bulan Dhesta masyarakat suku Tengger mengadakan tradisi Unanunan.

\section{Kearifan Lokal Unan-Unan}

Pada saat pelaksanaan ritual Unanunan kepala kerbau dihias dan diletakan diatas ancak/keranda. Diatas ancak diletakan sesaji berupa sate kerbau sebanyak 100 tusuk, 100 tumpeng dan 100 jajanan yang dibungkus dengan daun Klotok. Selanjutnya ancak diarak oleh seluruh warga suku Tengger menuju sanggar pamujan yang berada diatas bukit takjauh dari perkampungan warga. Arakarakan dipimpin oleh dukun, kepala Desa, tokoh agama dan tokoh adat suku Tengger.

Tradisi Ojung atau adu pukul dengan batang rotan yang digunakan oleh pendekar Ojung sebagai senjata dan tameng. Panjang rotan sekitar 1 meter dan berdiameter 3 $\mathrm{cm}$. Selama pertandingan, musik tradisional yang disebut Okol dan Kidungan Madura menambah semarak tradisi Ojung tersebut. Musik yang jarang dijumpai di daerah lain ini terdiri dari 3 buah Dung-Dung (akar pohon siwalan) yang dilubangi ditengahnya sehingga bunyinya seperti bas, dan kerca serta satu alat musik kleningan sebagai pengatur lagu.

Upacara Karo adalah perayaan besar desa, kata Karo berarti dua atau keduanya. Kegiatan tersebut dilaksanakan pada bulan Karo (bulan kedua di kalender suku Tengger). Upacara Karo memiliki histori tentang abdi kanjeng Nabi yang bernama Setya dan Abdi dari Aji Saka yang bernama Setuhu. Keduanya berselisih, tapi tidak ada yang menang dan sama-sama gugur sehingga upacara ini di gelar sebagai peringatan agar menghindari musibah karena salah paham.

Saat melakukan upacara Karo, masyarakat Ngadas biasanya memakai pakaian baru dengan diawali upacara ritual di rumah kepala desa setempat. Warga yang membawa aneka makanan ditata sedemikian rupa. Upacara ritual ini dipimpin oleh seorang Dukun desa.

\section{Galungan}

Hari raya Galungan ini adalah hari raya kemenangan setelah melaksanakan hari raya Nyepi.Untuk itu seluruh umat Hindu bersama-sama pergi ke Pura untuk 
melakukan persembahyangan kepada sang Hyang Widi.

Galungan sendiri berasal dari bahasa Jawa Kuno yang memiliki arti 'menang'. Dan juga kata Galungan memiliki makna yang serupa dengan Dungulan yang berarti menang. Selain merupakan sebuah perayaan hari kemenangan, perayaan Hari Galungan ini juga memperingati terciptanya alam semesta jagad raya beserta isinya.

Kerukunan beragama terwujud dalam praktik-praktik keseharian di masyarakat Desa Ngadas. Terlebih spasial atau pola hunian pemukiman di desa Ngadas tidak ada pembagian khusus berdasarkan agama. Semua umat beragama di Desa Ngadas hidup secara membaur antara umat agama satu dengan agama lainnya.

Hal ini menandakan tidak ada persoalan dalam perbedaan agama, dan rasa kebersamaan sebagai warga Ngadas sangat kuat mendukung terwujudnya kerukunan ini. Praktik saling menghormati ditunjukkan dengan kesediaan untuk memenuhi undangan dari orang lain. Dalam tradisi Desa Ngadas, undangan ini disebut Sayan, apabila seseorang mendapatkan undangan untuk menghadiri hajatan warga yang lain maka ia harus hadir. Tradisi membagi makanan juga biasa dilakukan, terutama pada saat hari raya. Pola pemukiman yang membaur menjadikan warga Desa Ngadas hidup berdampingan tanpa membedakan agama. Pada hari raya Karo, terdapat tradisi Genten Cecelukan, yaitu tradisi saling mengundang makan tetangga.

Praktik kerjasama dalam urusan kemasyarakatan maupun pribadi juga hal yang umum dilakukan oleh warga Desa Ngadas. Dalam kegiatan umum kegiatan seperti gotong-royong dan kerja bakti dilakukan bersama-sama oleh warga tanpa membeda-bedakan agama, seperti perbaikan jalan, dan juga pembangunan sarana umum jalan dan sekolahan. Bahkan dalam pembangunan rumah ibadah di Desa Ngadas, semua warga turut berpartisipasi.
Salah satu kearifan lokal masyarakat Suku Tengger di Desa Ngadas adalah cara berpakaian mereka. Baju adat Tengger berwarna hitam, sehelai kain baju tanpa jahitan, udeng dan kain selempang berwarna kuning, hal ini sesuai dengan yang diperoleh sebagai warisan dari nenek moyang Suku Tengger. Untuk menghalau cuaca yang dingin masyarakat Tengger selalu memakai sarung baik itu laki-laki maupun perempuan. Laki-laki di Desa Ngadas biasanya memakai sarung dengan cara dikalungkan di leher mereka, tetapi di saat mereka bekerja biasanya sarung dipakai untuk penutup wajah dan kepala untuk menghalau debu dan memudahkan mereka saat bekerja. Dan untuk acaraacara tertentu mereka memakai sarung sebagai lendeh/bebet, misalnya menghadiri acara-acara keluarga dan acara-acara resmi di desa. Sedangkan untuk perempuan, mereka biasanya memakai kain robogan/sewek yang ditalikan/dipakai sebetan dan diselempangkan di lehernya, biasanya kain diselempangkan ke samping, tetapi apabila mereka bekerja kain diselempangkan ke belakang, agar tidak menganggu dalam melakukan pekerjaan. Terkadang kain juga dipakai sebagai ikat perut/sembung, ketika mereka sedang bekerja di ladang-ladang pertanian.

Tingkat sosial ekonomi masyarakat Desa Ngadas Kecamatan Poncokusumo Kabupaten Malang sangat beragam dan kompleks. Kondisi mata pencaharian mayoritas di bidang pertanian dan lainnya sektor pariwisata sebagai pendukung mata pencaharian utama, masyarakat Desa Ngadas mayoritas terspesifikasi pada satu bidang yaitu pertanian. Sosial masyarakat berawal dari adanya proses sosial atau interaksi sosial yang merupakan cara-cara berhubungan yang dapat dilihat apabila para individu dan kelompok-kelompok saling bertemu dan menentukan sistem serta bentuk hubungan tersebut atau apa yang 
akan terjadi apabila adanya perubahanperubahan yang menyebabkan goyahnya cara-cara hidup yang telah ada. Atau dengan kata lain, proses sosial diartikan sebagai pengaruh timbal balik antara berbagai segi kehidupan bersama. Pola perilaku sosial dan ekonomi pada masyarakat Desa Ngadas sangat menjunjung tinggi kekeluargaan dan menanamkan nilai-nilai kebersamaan. Sikap gotong royong melingkupi kehidupan masyarakat Desa Ngadas pada setiap aspek kehidupannya. Selain pada penyelenggaraan ritual-ritual, pembangunan balai desa hingga rumah warga juga dilakukan secara gotong royong. Selain itu, setiap warga yang keluar dari Desa untuk belajar di luar daerah, selalu diminta kembali. Dengan demikian, warga yang telah memperoleh ilmu dapat diterapkan di desanya untuk membangun desa secara keseluruhan.

Tingkat sumber daya manusia Desa Ngadas termasuk menengah ke bawah dan kebanyakan pendidikannya hanya tamat SD. Mata pencaharian desa Ngadas ini mayoritas adalah petani. Selain kekayaan budaya yang terdapat didesa ini, hasil buminya pun sangat melimpah seperti kentang, kubis, bawang merah dll. Potensi alam sekitar desa Ngadas ini pun sangat menarik. Interaksi sosial dalam masyarakat desa Ngadas juga sangat baik, ditunjukkan dengan adanya kegiatan gotong royong kekeluargaan dan saling membahu satu sama lain.

Pendidikan terbagi menjadi beberapa jenjang, dan uniknya ada yang sudah sekolah sampai jenjang menengah dan tinggi tetapi tetap kembali sebagai petani dan wisata. Ada juga beberapa anak muda yang menjadi tour guide, dan bekerja di hotel, sebagian dari yang lulusan SMK Pariwisata. Tetapi pendidikan juga berpengaruh terhadap ekonomi, terutama bagi yang dapat bekerja pada sektor lain seperti menjadi pegawai atau guru yang dapat meningtkan kualitas ekonomi.
Bagi masyrakat Ngadas, hutan adalah salah satu kawasan yang sangat dihormati keberadaannya. Bahkan dukun di Desa Ngadas menegaskan bahwa hutan adalah bagian dari ritual upacara adat suku Tengger, karena bahan-bahan ritual diperlukan dari hutan. Sehingga hutan sangat penting bagi kehidupan warga Ngadas Tengger, merusak hutan sama halnya akan mengganggu upacara-upacara adat.

Demikian juga hal yang menyangkut dengan pohon di hutan bahwa diyakini pohon di hutan itu ada yang hidup di dalamnya, baik pada tubuh pohon itu sendiri, dimana hidup itu diberi oleh ibu bumi, atau makhluk halus maupun makhluk hidup lainnya yang menempatinya. Menebang pohon sembarangan sama halnya menghilangkan kehidupan pohon dari ibu bumi dan mengusir makhluk yang menempatinya tanpa sopan santun atau permisi, dan perilaku ini sangat tidak bermoral.

Seiring dengan perkembangan dan pembangunan ekonomi suku Tengger, pariwisata yang ada dalam Desa Ngadas menjadi salah satu penyumbang devisa cukup besar bagi kesejahteraan masyarakat Desa Ngadas. Alasan utama pengembangan pariwisata pada suatu daerah tujuan wisata, baik secara lokal, regional atau ruang lingkup nasional pada suatu negara sangat erat kaitannya dengan pembangunan perekonomian daerah atau negara tersebut. Dengan kata lain, pengembangan kepariwisataan pada suatu daerah tujuan wisata selalu akan diperhitungkan dengan keuntungan dan manfaatnya bagi rakyat banyak. Alasan kedua pengembangan pariwisata itu lebih banyak bersifat nonekonomis, adanya kegiatan kepariwisataan akan menimbulkan hasrat dan keinginan untuk memelihara semua aset wisata yang dimaksud (Yoeti, 1997;33-34).

Upaya pengembangan Ekowisata Desa Ngadas memerlukan kajian yang hatihati. Hal ini karena Kecamatan 
Poncokusumo masuk prioritas utama dalam arahan pengembangan wisata Kabupaten Malang. Sinergi dan momentum pengembangan ekowisata Ngadas dalam arahan wisata Poncokusumo perlu dipelihara. Karena itu, pengembangannya perlu meletakkan kepada konsep pengelolaan ekowisata dan TNBTS secara benar.

\section{Kesimpulan}

Dari pembahasan dapat disimpulkan bahwa:

1. Desa Ngadas tergolong dalam zona pemanfaatan tradisional.

2. Unan-unan merupakan salah satu budaya yang dimiliki oleh suku Tengger, tradisi ini dilakukan dalam jangka waktu lima tahun sekali.

3. Desa Ngadas memiliki banyak kearifan local seperti, Unan-unan, Galungan, festival Ojung, dan upacara Karo.

4. Kearifan lokal di Desa Ngadas sangat mempengaruhi terhadap perkembangan ekowisata.

\section{Saran}

1. Bagi Desa Ngadas:

Tetap mempertahankan adat istiadat yang diwariskan oleh para leluhur

2. Bagi Taman Nasional:

Perlu adanya sosisalisasi atau penyuluhan yang lebih intensif.

\section{DAFTAR PUSTAKA}

Alfi, 2018. Taman Nasional Bromo Tengger Semeru. Diakses tanggal 1 Juli 2019. https://foresteract.com.

Andi M. Akhmar dan Syarifuddin, 2007. Mengungkap Kearifan Lingkungan Sulawesi Selatan, PPLH Regional Sulawesi, Maluku dan Papua, Kementerian Negara Lingkungan Hidup RI dan Masagena Press, Makasar.
Falahi M. 2018 Tradisi Tengger Menentukan Penanggalan Demi Kesuburan. https://www.mongabay.co.id

Fandelli, 2000. Konsep Ekowisata. Diakses tanggal 4 Juli 2019. https://www.academia.edu

Francis Wahono, 2005. Pangan, Kearifan Lokal dan Keanekaragaman Hayati, Penerbit Cindelaras Pustaka Rakyat Cerdas, Yogyakarta.

Hasan, 2016. Desa Ngadsa. Diakses 10 April 2019. https://ngalam.co.id

Mulyoutami,,

R.Rismawan,L.Joshi,2009.Local

knowledge and Management of Simpukng (forest gardens) among the Dayak people in East Kalimantan, Indonesia. Forest Ecology and Management257(2009):2054-2061.

Puspita Putri, 2017. Upacara Kasada. Diakses tanggal 4 Juli 2019. https://bobo.grid.id.

Rahayu Siwi, 2015. Definisi Upacara Kasada. Diakses tanggal 4 Juli 2019 https://www.pegipegi.com

Salim, Agus. 2008. PengantarSosiologi Mikro.Yogyakarta: Pustaka Pelajar.

Sayektiningsih, 2008. Strategi Pengembangan Pendidikan Konservasi Pada Masyrakat Suku Tengger di Enclave TNBTS http://journal.ipb.ac.id

Sedyawati, 2006. Kearifan Lokal. Diakses tanggal $10 \quad$ Juli 2019 https://kajianpustaka.com

Sony Keraf, 2002. Etika lingkungan, (Jakarta : penerbit buku kompas). 